\title{
Substrate effect on supramolecular self-assembly: from semiconductors to metals
}

\author{
Takayuki Suzuki, ${ }^{a}$ Theresa Lutz, ${ }^{a}$ Dietmar Payer, ${ }^{a}$ Nian Lin, ${ }^{a b}$ Steven L. Tait, ${ }^{a c}$ \\ Giovanni Costantini*ad and Klaus Kern ${ }^{a e}$
}

Received 12th March 2009, Accepted 8th May 2009

First published as an Advance Article on the web 10th June 2009

DOI: $10.1039 / \mathbf{b} 905125 b$

Terephthalic acid (TPA) deposited on $\mathrm{Si}(111)-7 \times 7, \operatorname{Si}(111)-\sqrt{3} \times \sqrt{3}-\mathrm{Ag}$ and $\mathrm{Ag}(111)$ has been studied as a model system to understand how much passivated semiconductor surfaces differ from semiconductor and metal surfaces in respect of supramolecular self assembly. By scanning tunneling microscopy it is found that TPA molecules do not form any ordered supramolecular structure on the pristine semiconductor surface, due to a strong molecule-substrate interaction. On the contrary, TPA has a weaker interaction with $\mathrm{Si}(111)-\sqrt{3} \times \sqrt{3}-\mathrm{Ag}$, leading to the formation of an ordered supramolecular layer stabilized by carboxyl hydrogen bonds. These structures are very similar to the supramolecular layer of TPA formed on $\operatorname{Ag}(111)$, indicating that the two substrates behave similarly for what concerns the adsorption of functional organic molecules. However, the deposition of Fe on the TPA layers on $\mathrm{Si}(111)-\sqrt{3} \times \sqrt{3}-\mathrm{Ag}$ does not induce the formation of two-dimensional metal-organic frameworks which, on the contrary, readily develop on $\operatorname{Ag}(111)$. Possible origins of this difference are discussed.

\section{Introduction}

Functionalization of semiconductor surfaces with organic molecules has attracted much interest recently. ${ }^{1-3}$ It can be used to develop organic-semiconductor hybrid systems, such as molecular electronic devices, ${ }^{4,5}$ optical devices ${ }^{2}$ and chemical sensors. ${ }^{2,6,7}$ However, unlike metal substrates, semiconductor surfaces have a high density of dangling bonds which represent energetically favorable binding sites for organic molecules. This can result in irreversible chemisorption, or even dissociative adsorption, and in a reduced surface diffusivity. ${ }^{3}$ On the contrary, high surface mobility is a necessary condition for the formation of ordered supramolecular structures. Surface dangling bonds also impose stringent lattice-matching conditions on the growth of the organic layer, leading to poor crystallinity. One promising possibility to overcome these limitations is to deactivate the dangling bonds through passivation with other atoms such as hydrogen, chalcogens or noble metals. ${ }^{8}$

The main aim of the present study is to assess the effect of passivation of semiconductor surfaces by noble metal atoms on supramolecular self-assembly, compared to semiconductor and metal surfaces. To this end, we investigated and compared the deposition of benzene-1,4-dicarboxylic acid $\left(\mathrm{C}_{6} \mathrm{H}_{4}(\mathrm{COOH})_{2}\right.$, terephthalic acid, TPA $)$ on the pristine

${ }^{a}$ Max Planck Institute for Solid State Research, Heisenbergstrasse 1, 70569, Stuttgart, Germany

${ }^{b}$ Department of Physics, The Hong Kong University of Science and Technology, Clear Water Bay, Kowloon, Hong Kong, China

${ }^{c}$ Department of Chemistry, Indiana University, Bloomington, IN 47405, USA

${ }^{d}$ Department of Chemistry, University of Warwick, Coventry, United Kingdom CV4 7AL. E-mail: g.costantini@warwick.ac.uk

${ }^{e}$ Institut de Physique de la Matière Condensée, Ecole Polytechnique Fédérale de Lausanne, CH-1015, Lausanne, Switzerland
$\operatorname{Si}(111)-7 \times 7,{ }^{9}$ passivated $\operatorname{Si}(111)-\sqrt{3} \times \sqrt{3}-\mathrm{Ag}^{10}$ and clean $\operatorname{Ag}(111)$ surfaces.

TPA is considered as a prototypical functional molecule. It has a simple planar structure formed by an aromatic ring and two carboxylic moieties (Fig. 1). It can mediate $\pi-\pi$ intermolecular stacking, hydrogen bonding (denoted as $\mathrm{H}$-bonding hereafter) and metal-organic coordination. TPA is one of the most frequently used molecular linkers for the fabrication of three-dimensional (3D) metal-organic frameworks (MOFs) in solution coordination chemistry. ${ }^{11,12}$ The deposition of TPA on solid substrates has also been intensively investigated, particularly in the case of metals, including $\mathrm{Au}(111),{ }^{13} \mathrm{Pd}(111),{ }^{14}$ and $\mathrm{Cu}(001) .{ }^{15}$ For all these cases it has been reported that TPA, or its deprotonated terephthalate form, adsorbs with the phenyl ring parallel to the surface and arranges into a supramolecular layer stabilized by H-bonds. Furthermore, two-dimensional (2D) MOFs could be formed by co-adsorption of $d$-transition metal atoms such as $\mathrm{Fe}, \mathrm{Co}$ and $\mathrm{Cu} .{ }^{16-23}$ Due to its double-ended functionality, when TPA is absorbed in an upright geometry, it can be used for the organic passivation of inorganic surfaces such as $\mathrm{Cu}(110)^{24}$ and $\mathrm{TiO}_{2}{ }^{25} \mathrm{~A}$ perpendicular binding geometry has also been reported for the adsorption of a similar molecule, 2-(trifluoromethyl)-terephthalic acid $\left(\mathrm{C}_{6} \mathrm{H}_{3} \mathrm{CF}_{3}(\mathrm{COOH})_{2}\right)$, from solution onto fluorine-terminated $\mathrm{Si}(111) .{ }^{26}$ To the best

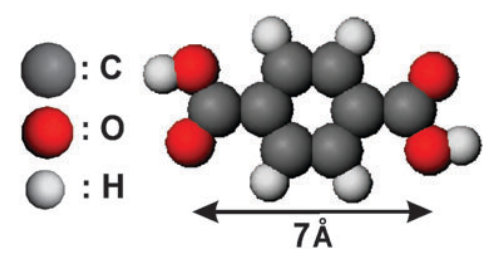

Fig. 1 Molecular structure of terephthalic acid (TPA). 
of our knowledge, however, there has not been any report so far about the deposition of TPA on pristine or passivated semiconductor surfaces.

The $\operatorname{Si}(111)-\sqrt{3} \times \sqrt{3}-\mathrm{Ag}$ surface is obtained by depositing one monolayer (ML) of silver on the $\mathrm{Si}(111)-7 \times 7$ substrate and represents a model passivated semiconductor surface for the growth of thin organic films. The adsorbed Ag atoms bind covalently to the Si atoms, leaving no dangling bonds on the surface and thus substantially diminishing its reactivity. Several groups have studied the adsorption of different types of molecules on $\mathrm{Si}(111)-\sqrt{3} \times \sqrt{3}-\mathrm{Ag}$, including pentacene, ${ }^{27,28} \mathrm{C}_{60},{ }^{29-31}$ phthalocyanines, ${ }^{32}$ 3,4,9,10-perylene tetracarboxylic dianhydride (PTCDA), ${ }^{33,34}$ perylene tetracarboxylic di-imide (PTCDI) ${ }^{34}$ adenine, ${ }^{35}$ and trimesic acid (TMA). ${ }^{36}$ All of the organic molecules above were reported to adsorb intact, in a flat geometry, and to form extended ordered layers on the substrate. Furthermore, even supramolecular open honeycomb networks could be obtained by co-adsorption of melamine with $\mathrm{PTCDI}^{37}$ or cyanuric acid (CA). ${ }^{38}$

Our measurements confirm that while the moleculesubstrate interactions are too strong on $\mathrm{Si}(111)-7 \times 7$ to allow formation of an ordered TPA monolayer, they become weaker and reversible enough on the passivated $\mathrm{Si}(111)-\sqrt{3} \times \sqrt{3}-\mathrm{Ag}$, so as to enable the growth of extended H-bonded supramolecular structures with many similarities to those on $\mathrm{Ag}(111)$. However, 2D MOFs do not form on $\mathrm{Si}(111)-$ $\sqrt{3} \times \sqrt{3}-\mathrm{Ag}$ when $\mathrm{Fe}$ atoms are co-deposited with TPA, while they readily develop on $\mathrm{Ag}(111)$.

\section{Experimental}

The experiments on the $\mathrm{Si}(111)$ substrates were carried out in a home-built, room-temperature scanning tunneling microscope (STM). The base pressures of the STM and the preparation chambers are $<1 \times 10^{-10} \mathrm{mbar}$ and $5 \times 10^{-10} \mathrm{mbar}$, respectively. The $\mathrm{Si}$ samples $(0.25 \sim 0.3 \times 1 \times 9 \mathrm{~mm})$ were cut from n-type phosphorus-doped $\mathrm{Si}(111)$ wafers $(0.007 \sim 0.013 \Omega \mathrm{cm}$, Siltronix). The Si samples were ultrasonically cleaned in pure ethanol, acetone and deionized water, and then introduced immediately into the UHV chamber. After being outgassed at $500{ }^{\circ} \mathrm{C}$ for several hours, the crystals were flashed to $1200{ }^{\circ} \mathrm{C}$ in order to obtain a clean $7 \times 7$ reconstruction which was always checked before every experiment by STM. For obtaining the $\mathrm{Si}(111)-\sqrt{3} \times \sqrt{3}-\mathrm{Ag}$ substrates, about $1 \mathrm{ML}$ of silver was deposited from a molybdenum crucible heated by electron bombardment onto the Si substrate held at $450{ }^{\circ} \mathrm{C}$. The TPA molecules $(\geq 99 \%$, powder, Fluka) were deposited onto the substrates held at room temperature from a heated glass crucible that was degassed before use. STM tips were electrochemically etched from tungsten wires. All STM measurements on the Si substrates were carried out at room temperature.

The experiments on the single crystal $\operatorname{Ag}(111)$ substrate (MaTecK) were carried out in a separate UHV system. The Ag surface was prepared in situ by cycles of sputtering with $\mathrm{Ar}^{+}$ions and annealing to $580{ }^{\circ} \mathrm{C}$. The TPA molecules were deposited at room temperature. Then, the Ag sample was

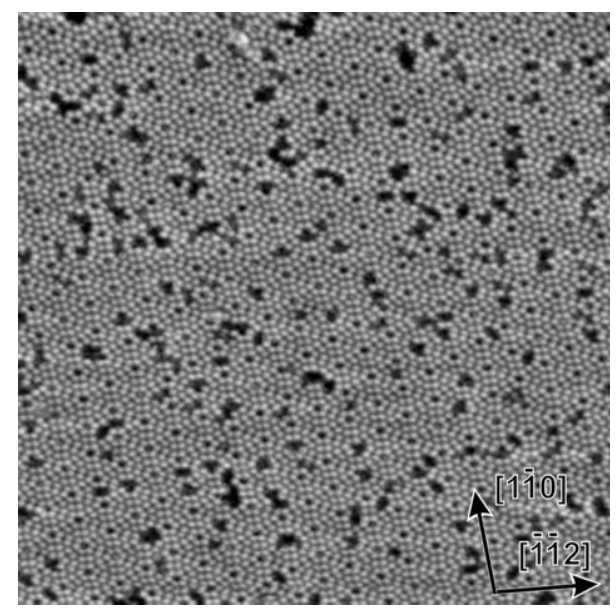

Fig. 2 Overview STM image after TPA deposition on the $\mathrm{Si}(111)-7 \times 7$ surface. The image size is $50 \times 50 \mathrm{~nm}$. Sample bias $\left(V_{\mathrm{s}}\right)=+1.9 \mathrm{~V}$, tunneling current $(I)=0.35 \mathrm{nA}$.

transferred to a second, home-built, low-temperature STM for imaging at approximately $5 \mathrm{~K}$.

\section{Results and discussion}

\subsection{TPA on $\mathrm{Si}(111)-7 \times 7$}

Fig. 2 shows an overview STM image of the $\operatorname{Si}(111)-7 \times 7$ surface exposed to a sub-ML dose of TPA. While there are only very few defects on the surface before the TPA deposition, many dark spots appear afterwards, which can therefore be assigned to the adsorbed TPA molecules. It is evident that TPA adsorbs randomly on the Si substrate and does not form any ordered supramolecular structure. A similar behavior has been observed for the deposition of many other organic molecules on $\mathrm{Si}$ substrates. ${ }^{1,3}$ This is an indication of a very strong interaction between the molecules and the $\operatorname{Si}(111)-7 \times 7$ surface which is characterized by a high density of Si dangling bonds (12 on the Si adatoms, 6 on the rest atoms and 18 on the dimers for each $7 \times 7$ unit cell). Adsorption of TPA on these sites happens most probably through the formation of irreversible covalent bonds, preventing the surface diffusion needed to form ordered molecular layers.

We have analyzed the different adsorption configurations that TPA adopts on the $\mathrm{Si}(111)-7 \times 7$ substrate, according to the STM images. This results in the classification of at least 10 different configurations appearing with different frequencies. Fig. 3(a)-(f) show STM images corresponding to the six most common ones. The unit cell of the $7 \times 7$ reconstruction is delimited by dotted lines in Fig. 3(a), and is schematically represented in Fig. $3(\mathrm{~g})$, as a reference. For the empty-state tunneling conditions $\left(V_{\mathrm{s}}=+1.8 \mathrm{~V}, I=0.2 \mathrm{nA}\right.$, ) each of the 12 bright protrusions observed in a $7 \times 7$ unit cell is the dangling bond of a Si adatom. The unfaulted (U) and faulted (F) half units of the $7 \times 7$ reconstruction are explicitly indicated in Fig. 3(a).

In Fig. 3(a) and (b), the dark spot associated with an adsorbed TPA molecule appears in the middle and at the bottom of the unit cell, respectively. In both cases it extends over the dangling bonds of a pair of $\mathrm{Si}$ adatoms aligned along 

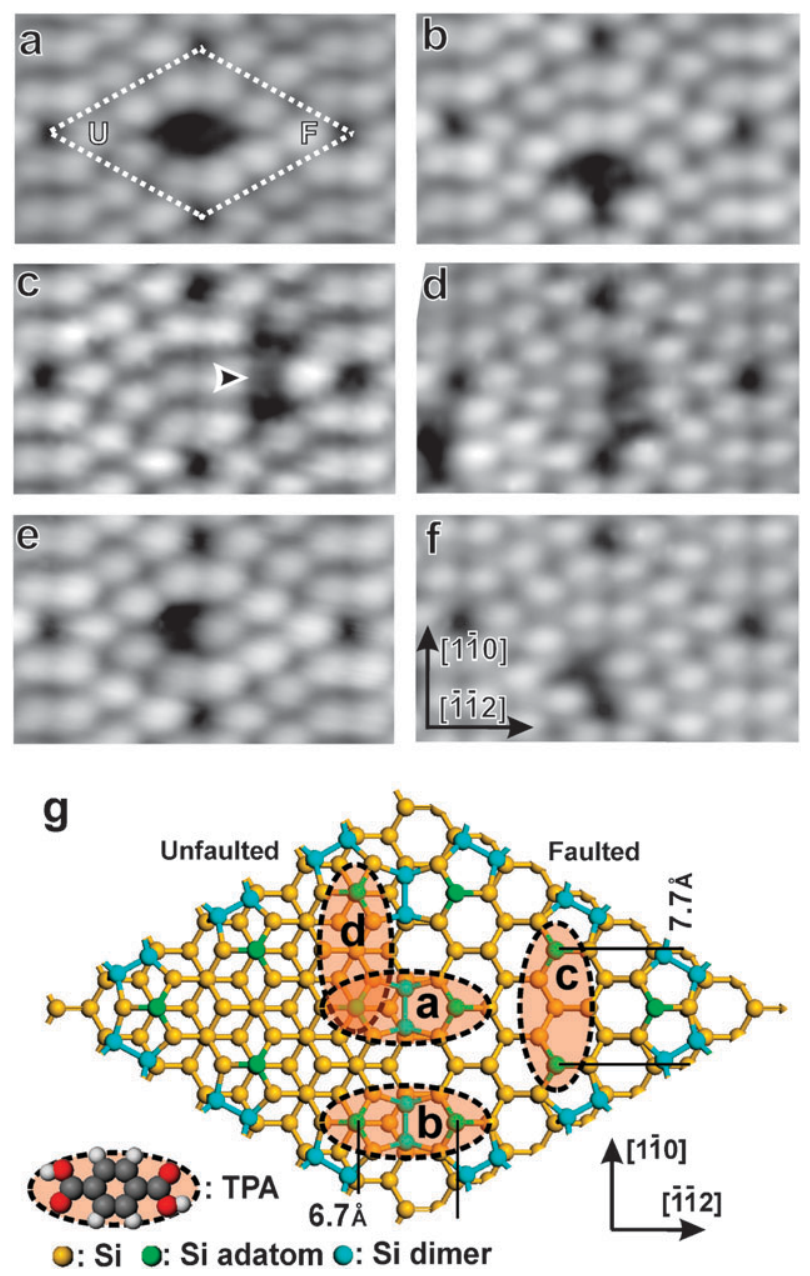

Fig. 3 (a)-(f) Detailed STM images of TPA adsorbed on the $\operatorname{Si}(111)-7 \times 7$ surface $\left(V_{\mathrm{s}}=+1.8 \mathrm{~V}, I=0.2 \mathrm{nA}\right)$. The unfaulted and the faulted half units are indicated by $\mathrm{U}$ and $\mathrm{F}$, respectively. (g) Schematic drawing of possible TPA adsorption configurations.

[1112] (ellipses a and b in Fig. 3(g)). The distance between each pair of $\mathrm{Si}$ adatoms is $6.7 \AA$, which is comparable to the length of the TPA molecule (about $7 \AA$ ). Therefore, we propose that, in these configurations, the molecule is predominantly bonded to the Si adatom dangling bonds and that the main axis of the TPA molecule lies parallel to the surface plane. About 20 and $40 \%$ of the adsorbed TPA molecules can be found in the configurations of Fig. 3(a) and (b), respectively.

In Fig. 3(c) and (d), the dark spot revealing the presence of a TPA molecule expands over the dangling bonds of two different pairs of [110]-aligned Si adatoms (ellipses $\mathrm{c}$ and $\mathrm{d}$ in Fig. 3(g), respectively). Also for these cases, the distance between such a pair of adatoms $(7.7 \AA)$ is close to the TPA length, suggesting that the molecule might be bonded in a geometry similar to that of Fig. 3(a) and (b). The brighter central part indicated by the arrow head in Fig. 3(c) could be due to a slightly stretched adsorption structure. About $25 \%$ of the TPA molecules can be found in the configuration corresponding to Fig. 3(c) and only a few \% in that of Fig. 3(d). Most of the remaining TPA molecules adsorb in the configurations shown in Fig. 3(e) (about $10 \%$ ) and Fig. 3(f) (a few $\%$ of the total). The fact that only a single Si adatom is covered in those cases might imply a non-planar adsorption geometry.

Although the faulted and the unfaulted halves of the $7 \times 7$ unit cell are not identical, adsorption configurations which mirror those shown in Fig. 3(c)-3(f) (where the dark spot is located on the other half of the unit cell) are observed with comparable frequencies. This indicates that TPA molecules do not distinguish between the faulted and unfaulted regions, further strengthening the hypothesis that they bind to the $\mathrm{Si}$ adatom dangling bonds. A precise determination of the type and geometry of this binding is beyond the scope of this paper. Nevertheless, reports in the literature indicate that organic molecules containing carboxyl moieties, such as formic acid, ${ }^{39,40}$ methacrylic acid $^{41}$ and glycine ${ }^{42}$ adsorb on $\operatorname{Si}(111)-7 \times 7$ in a deprotonated form through the formation of monodentate $\mathrm{Si}-\mathrm{O}$ bonds with $\mathrm{Si}$ adatoms. On the other hand, benzene has been shown to adsorb by establishing two $\mathrm{Si}-\mathrm{C}$ bonds with an adatom and a rest atom instead of with a pair of adatoms, because of its reduced size. ${ }^{3,43,44}$ As a consequence, we might speculate that TPA molecules adsorbed in the configurations of Fig. 3(a)-(d) might form two monodentate $\mathrm{Si}-\mathrm{O}$ bonds with $\mathrm{Si}$ adatoms in the positions indicated by the corresponding ellipses in Fig. 3(g). In configurations of Fig. 3(e) and (f), however, TPA could be bonded either through one of its carboxylate moieties, forming a monodentate $\mathrm{Si}-\mathrm{O}$ bond with a $\mathrm{Si}$ adatom, or through its aromatic ring, forming two $\mathrm{Si}-\mathrm{C}$ bonds, similar to benzene.

Although a more precise assignment needs further spectroscopic investigations (vibrational or electronic), our results clearly indicate that TPA strongly adsorbs on $\mathrm{Si}(111)-7 \times 7$ in many nonequivalent bonding geometries, which is not compatible with the formation of highly ordered supramolecular structures.

\subsection{TPA on $\operatorname{Si}(111)-\sqrt{3} \times \sqrt{3}-\mathbf{A g}$}

Fig. 4(a) shows a representative STM image after the sub-ML deposition of TPA on $\mathrm{Si}(111)-\sqrt{3} \times \sqrt{3}-\mathrm{Ag}$. The uncovered $\operatorname{Si}(111)-\sqrt{3} \times \sqrt{3}-$ Ag surface appears in the left hand side of the image, while the TPA molecular layer is visible on the right. It is clear that, at variance with the deposition on pristine $\operatorname{Si}(111)-7 \times 7$, the TPA molecules form a well-ordered layer, most probably due to a weaker molecule-substrate interaction. This is also indicated by the temperature of TPA desorption which sets in at $100 \sim 200{ }^{\circ} \mathrm{C}$. The TPA layer shows a modulation with a periodicity of about $2 \mathrm{~nm}$ along the [1112] direction, as indicated by the lines in the upper right part of Fig. 4(a). A similar modulation has also been reported for the adsorption of TMA on the same surface. ${ }^{36}$

In the detailed STM topography of Fig. 4(b) individual TPA molecules are imaged as brighter protrusions aligned along both the [ $[\overline{1} 12]$ and the [ $\overline{1} 10]$ directions (several of them are explicitly indicated by circles). Their precise appearance varies substantially from image to image and is dependent on the bias voltage of the tunneling junction and on the tip condition. However, their position and periodicity remain unchanged, as we directly verified by acquiring images in the same sample location at different bias voltages. Fig. 4(b) shows that the modulation of the TPA layer corresponds to an alternation of 

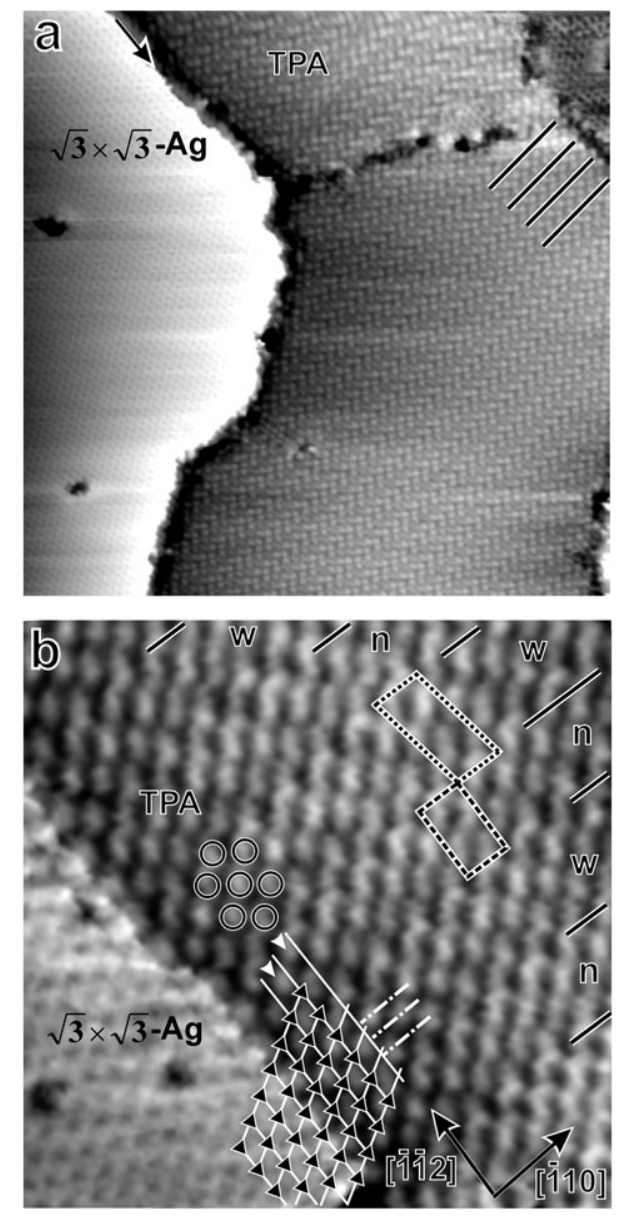

Fig. 4 (a) Overview STM image after the deposition of TPA on the $\operatorname{Si}(111)-\sqrt{3} \times \sqrt{3}-A g$ surface $\left(V_{\mathrm{s}}=-1.0 \mathrm{~V}, I=0.2 \mathrm{nA}\right)$. A single substrate step (height $3 \AA$ ) is indicated by an arrow between the bare $\operatorname{Si}(111)-\sqrt{3} \times \sqrt{3}-\mathrm{Ag}$ surface area and the TPA layer area. The image size is $50 \times 50 \mathrm{~nm}$. (b) Enlarged STM image of the TPA molecular layer $\left(V_{\mathrm{s}}=-1.8 \mathrm{~V}, I=0.2 \mathrm{nA}\right)$. There is no step between the substrate and the molecular layer. The former appears higher than the latter because of electronic or tip-induced effects. The image size is $14 \times 14 \mathrm{~nm}$.

narrower, n, and wider, $\mathrm{w}$, molecular stripes oriented along the [110] direction. The unit cells of the $\mathrm{n}$ and the $\mathrm{w}$ stripes are different from each other, as indicated by the dashed rectangle and the dotted parallelogram drawn in Fig. 4(b), respectively. In the specific case of Fig. 4(b), the $n$ and the w stripes appear alternately in a nwnw sequence but other irregular sequences such as nww or nnw are also frequently observed.

STM images such as Fig. 4(b), where the TPA layer is imaged at high resolution together with the $\operatorname{Si}(111)-\sqrt{3} \times \sqrt{3}-\mathrm{Ag}$ substrate, can be used to precisely determine the periodicity of the molecular superstructure. The lattice of the $\sqrt{3} \times \sqrt{3}$ reconstruction is explicitly shown in the lower part of Fig. 4(b), with black triangles indicating the positions of the $\mathrm{Si}$ trimers in the honeycomb-chained-triangle structure (these are typically imaged as darker depressions in filled state STM images). ${ }^{45}$ Along [1112] the molecules appear to be located in between the $\mathrm{Si}$ trimer rows, (white arrow heads in 4(b)), implying that the molecular layer is commensurate with the substrate along [110]. This also indicates that the aromatic part of the TPA molecule preferentially avoids the Si trimers and absorbs close to the $\mathrm{Ag}$ atoms where the highest density of occupied states is concentrated. On the contrary, the intermolecular distance along [ $\overline{1} \overline{1} 2]$ is smaller than the unit length of the $\operatorname{Si}(111)-\sqrt{3} \times \sqrt{3}-\mathrm{Ag}$ substrate, as shown by the dash-dotted lines in Fig. 4(b).

Fig. 5 shows a possible structural model for the TPA supramolecular layer which is consistent with the experimental observations. TPA molecules adsorb with their plane parallel to the substrate, their phenyl rings close to the Ag atoms and their main axis along the [110] direction. ${ }^{46}$ They form [110]-oriented molecular rows which are held together by stronger $\mathrm{O}-\mathrm{H} \cdots \mathrm{O}$ dimeric $\mathrm{H}$-bonds (intra-row) and weaker $\mathrm{C}-\mathrm{H}$ - O O H-bonds (inter-row), resulting in a brick wall-like molecular arrangement. The length of the dimeric H-bond is equal to $3.5 \AA$ for both the $\mathrm{n}$ and $\mathrm{w}$ stripes, which is comparable to that observed on metal substrates. The interrow distance between [110]-oriented molecular rows is longer in the $\mathrm{n}$ regions $(5.0 \AA)$ than in the w regions $(4.7 \AA)$, which is in good agreement with the average value of $\sim 5 \AA$ determined from the STM images. The corresponding unit cells can be expressed in matrix notation as

$$
\left(\begin{array}{cc}
3 & 0 \\
-3 & 6
\end{array}\right)
$$
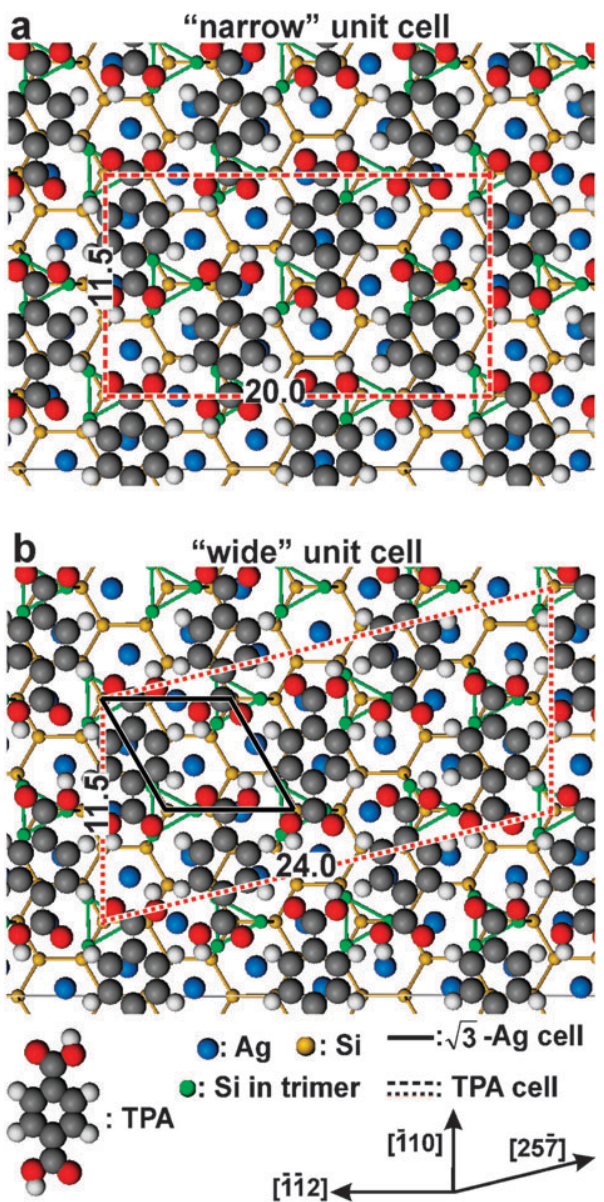

Fig. 5 Schematic drawings of possible structural models for the TPA molecular layer on $\mathrm{Si}(111)-\sqrt{3} \times \sqrt{3}-\mathrm{Ag}$ for (a) the $\mathrm{n}$ and (b) the $\mathrm{w}$ regions. 
and

$$
\left(\begin{array}{cc}
3 & 0 \\
-2 & 7
\end{array}\right),
$$

and are indicated by dashed and dotted lines in Fig. 5(a) and (b), respectively. From the STM experiments, it is difficult to determine whether TPA molecules are deprotonated as observed on some metal substrates ${ }^{13,14}$. Further spectroscopic studies are needed in order to determine this issue.

\subsection{TPA on $\operatorname{Ag}(111)$}

Fig. 6 shows an STM image of TPA layers formed on the $\operatorname{Ag}(111)$ surface. The large size of the molecular islands and the absence of stray molecules indicate a high mobility of TPA on the $\operatorname{Ag}(111)$ surface. The molecules form a well-defined, brick wall-like ordered layer which appears to be nearly identical to that observed by Clair et al. on $\mathrm{Au}(111) .^{13}$ Similarly to the $\operatorname{Si}(111)-\sqrt{3} \times \sqrt{3}-\mathrm{Ag}$ case, the TPA molecules arrange head-to-head in rows so that dimeric $\mathrm{H}$-bonds are formed between the carboxyl end groups. The molecular spacing along these rows is $10.0 \pm 0.5 \AA$, which corresponds to a H-bond length of $\sim 2.0 \AA$, similar to the values reported for $\mathrm{Au}(111)$ and measured on $\mathrm{Si}(111)-\sqrt{3} \times \sqrt{3}-\mathrm{Ag}$. Across the rows, the molecules show a very regular spacing of $6.1 \pm 0.5 \AA$, which is most probably regulated by an attractive electrostatic or H-bond type interaction, which is similar to the inter-row distances measured on $\operatorname{Si}(111)-\sqrt{3} \times \sqrt{3}-\mathrm{Ag}: 4.7$ and $5.0 \AA$ for $\mathrm{n}$ and $\mathrm{w}$ stripes, respectively. The modulation of the TPA layer seen on the $\mathrm{Si}(111)-\sqrt{3} \times \sqrt{3}-\mathrm{Ag}$ surface is not observed on $\mathrm{Ag}(111)$. This is most probably due to a spatial modulation of the adsorption potential on the passivated semiconductor substrate which, contrarily, is much smoother on the metal substrate. In turn, this could be due to the local electronic density of states being uniform on $\mathrm{Ag}(111)$ but highly inhomogeneous on $\mathrm{Si}(111)-\sqrt{3} \times \sqrt{3}-\mathrm{Ag}$.

Both TPA with intact ${ }^{13,15}$ and with deprotonated carboxylic acid groups ${ }^{14}$ have been reported to adopt a brick wall-like ordering on metal substrates. However, the deprotonation of benzene carboxylic acids on metal substrates needs to be catalyzed either by a reactive surface ${ }^{14,21}$ or by metal adatoms. $^{47}$ This was not observed for TPA on Au(111) ${ }^{13}$ nor for TMA on $\operatorname{Ag}(111)$ at room temperature. ${ }^{47}$ As a

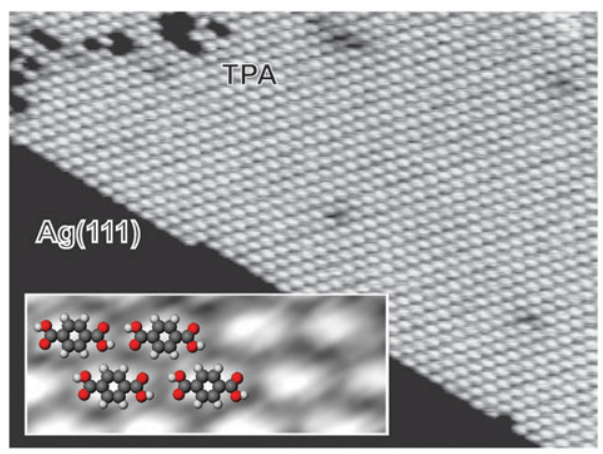

Fig. 6 STM image after the deposition of TPA on $\operatorname{Ag}(111)(36 \times 27 \mathrm{~nm})$. TPA molecules pack tightly on the surface to form large islands stabilized by intermolecular hydrogen bonding. Inset shows detail of the supramolecular structure $(4.1 \times 1.5 \mathrm{~nm})$. consequence, we speculate that TPA also adsorbs on $\mathrm{Ag}(111)$ in its intact acidic form.

\subsection{Fe deposition onto the TPA layer on $\operatorname{Ag}(111)$ and $\mathrm{Si}(111)-\sqrt{3} \times \sqrt{3}-\mathrm{Ag}$}

Planar benzene carboxylic acids were shown to form 2D MOFs when deposited onto metal substrates together with various $d$-transition metals such as $\mathrm{Fe}, \mathrm{Co}$ and $\mathrm{Cu} .{ }^{16-23}$ These frameworks are characterized by a high degree of perfection since their assembly is based on reversible interactions which allow self-selection, -recognition and -correction processes to occur. $^{22}$ It has been recently demonstrated that, similarly to their 3D counterparts, 2D MOFs are also stabilized by genuine charge-transfer coordination bonding and that the metallic centers are characterized by well-defined oxidation states. ${ }^{23}$ Such systems might be interesting not only as ordered 2D patterns with possible applications in host-guest reactions, nano reactors, etc. but also for the catalytic and magnetic properties of low-coordinated metallic centers. In particular, TPA has shown a great versatility as a molecular elementary building block for 2D MOFs on various substrates.

On $\mathrm{Ag}(111)$ the sequential deposition of TPA and Fe at room temperature followed by annealing at $130{ }^{\circ} \mathrm{C}$ results in formation of large domains of a highly ordered open lattice
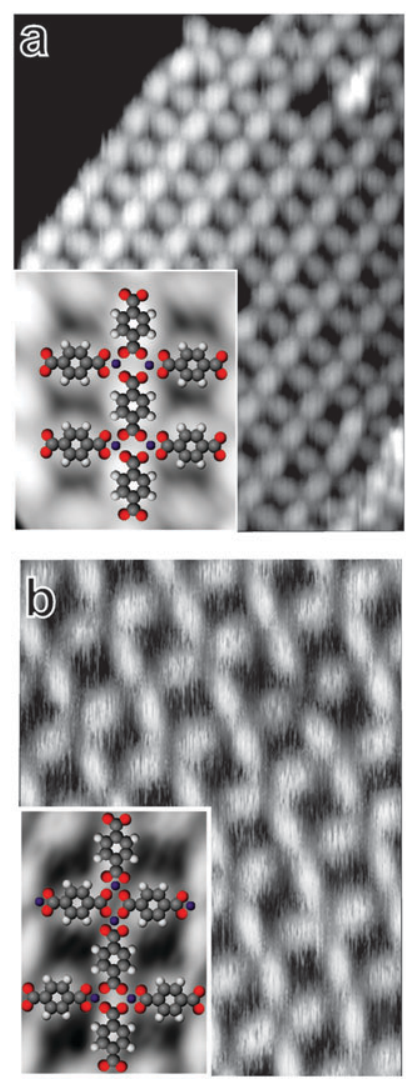

Fig. 7 STM images after the Fe deposition on the TPA molecular layer on $\mathrm{Ag}(111)$. Two types of 2D metal-organic networks are formed and co-exists on the surface: (a) rectangular and (b) square networks, as discussed in the text. The image sizes are (a) $12 \times 18 \mathrm{~nm}^{2}$ and (b) $7 \times$ $11 \mathrm{~nm}^{2}$, respectively. Insets ((a) $3.0 \times 3.5 \mathrm{~nm}^{2}$ and (b) $3.0 \times 4.0 \mathrm{~nm}^{2}$, respectively) show details of the networks. 
structure, as shown in the STM images in Fig. 7. The lattice structure and size are very similar to the diiron-terephthalate 2D MOFs formed on $\mathrm{Cu}(100)^{16,17}$ and $\mathrm{Au}(111)^{19}$ and to the dicobalt-terephthalate formed on $\mathrm{Au}(111){ }^{20}$ Two phases coexist on the $\operatorname{Ag}(111)$ surface which differ in the orientation of neighboring Fe dimers. Similarly to what is observed on $\mathrm{Cu}(100),{ }^{16}$ the relative orientation of the dimers can either be the same for every node of the network (rectangular phase, Fig. 7(a)) or it can be alternately perpendicular (square phase, Fig. 7(b)). In the first case, half of the TPA molecules form two bidentate bonds with $\mathrm{Fe}$ dimers (bridging position) and the other half form two monodentate bonds (axial dimer position). In the latter case, each TPA molecule forms one bidentate and one monodentate bond with Fe centers. The rectangular nanopores (Fig. 7(a)) are $(15.8 \pm 0.5) \times(10.7 \pm 0.5) \AA$ in size while the square ones (Fig. 7(b)) have a nanopore sidelength of $13.3 \pm 0.5 \AA$. Because of their very similar overall extension (domain size), the two phases must be nearly equivalent in energy.

In order to investigate whether similar 2D MOFs can form also on a passivated semiconductor substrate, we deposited $\mathrm{Fe}$ on the TPA layers formed on $\operatorname{Si}(111)-\sqrt{3} \times \sqrt{3}-\mathrm{Ag}$. The STM image in Fig. 8 clearly demonstrates that, in contrast to the case of metal substrates, no 2D MOFs are formed. The original $\mathrm{H}$-bonded TPA layer stays intact (including its modulation) and bright protrusions can be observed, which we identify as $\mathrm{Fe}$ or Fe-silicide clusters. Sample annealing up to $100{ }^{\circ} \mathrm{C}$ does not produce any noticeable change, while for higher temperatures, the TPA molecules start to desorb.

One of the possible reasons explaining why the 2D MOFs do not develop on the $\mathrm{Si}(111)-\sqrt{3} \times \sqrt{3}-\mathrm{Ag}$ surface might be that Fe forms 3D Fe-silicide islands on this surface, ${ }^{48}$ while it adopts an epitaxial layer-by-layer growth mode on $\operatorname{Ag}(111) .{ }^{49}$ Therefore, the tendency toward intermixing of $\mathrm{Fe}$ with $\mathrm{Si}$ might prevent the formation of iron-terephthalate networks on $\mathrm{Si}(111)-\sqrt{3} \times \sqrt{3}-\mathrm{Ag}$. A second impediment to $2 \mathrm{D} \mathrm{MOF}$ assembly is the different catalytic effect of the two substrates for carboxylic acid deprotonation. Similarly to what happens in solution chemistry, the formation of metal-organic coordination bonds on surfaces requires the deprotonation

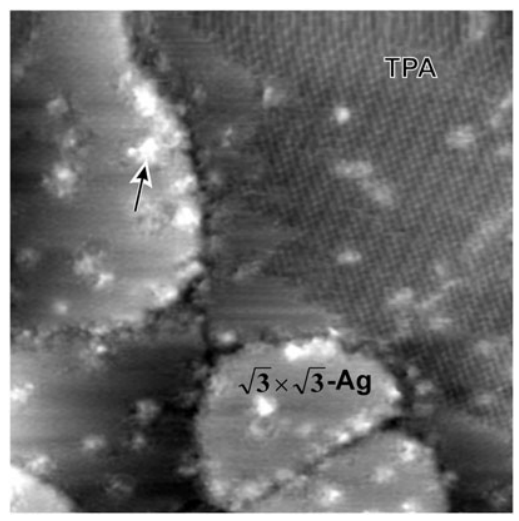

Fig. 8 STM image after the Fe deposition on the TPA molecular layer on $\mathrm{Si}(111)-\sqrt{3} \times \sqrt{3}-\mathrm{Ag}\left(V_{\mathrm{s}}=-1.0 \mathrm{~V}, I=0.2 \mathrm{nA}\right)$. The image size is $50 \times 50 \mathrm{~nm}$. An Fe or Fe-silicide cluster is indicated by an arrow. of the carboxylic acid groups. While this occurs readily on certain substrates such as $\mathrm{Cu}(100),{ }^{15,23} \mathrm{Cu}(110)^{21}$ or $\mathrm{Pd}(111),{ }^{14}$ it does not take place spontaneously on $\mathrm{Au}(111)^{13}$ or $\operatorname{Ag}(111)$, as demonstrated by the results shown in section 3.3. On these latter surfaces, however, the deprotonation of the carboxylic groups is induced by the deposition of $\mathrm{Fe},{ }^{19} \mathrm{Co}^{20}$ or $\mathrm{Cu}$ adatoms, ${ }^{47}$ enabling the formation of $2 \mathrm{D}$ MOFs (see Fig. 7). However, in the present case, Fe co-deposition with TPA on the $\mathrm{Si}(111)-\sqrt{3} \times \sqrt{3}-\mathrm{Ag}$ surface does not lead to deprotonation of the carboxylic acid groups. This would imply that catalysis of the deprotonation process by Fe adatoms requires a specific surface or interface electronic structure between TPA and the "true" metallic substrate, which is different from that on a passivated semiconductor substrate.

\section{Summary}

We have presented an STM investigation of supramolecular self-assembly on semiconductor, passivated semiconductor and metal surfaces, using the adsorption of TPA on $\operatorname{Si}(111)-7 \times 7, \operatorname{Si}(111)-\sqrt{3} \times \sqrt{3}-\mathrm{Ag}$ and $\mathrm{Ag}(111)$ as model systems. Due to a strong molecule-substrate interaction, TPA does not form any ordered molecular layer but adsorbs randomly on the $\mathrm{Si}(111)-7 \times 7$ surface with several adsorption configurations. On the contrary, TPA forms an ordered layer stabilized by intermolecular H-bonds on $\mathrm{Si}(111)-\sqrt{3} \times \sqrt{3}-\mathrm{Ag}$. A very similar brick wall-like supramolecular layer is observed for the deposition of TPA on $\operatorname{Ag}(111)$, indicating that both substrates allow similar supramolecular self-assembly of organic molecules. On the other hand, the deposition of $\mathrm{Fe}$ on the TPA layers induces the formation of 2D MOFs only for the $\operatorname{Ag}(111)$ substrate. Possible reasons for this difference might be the tendency of Fe to intermix with $\mathrm{Si}$ and/or the catalytic role of metal substrates in the deprotonation of carboxylic groups. Although further studies are needed to clarify these issues, our investigation clearly demonstrates that metal-passivated semiconductor surfaces behave similarly to "true" metallic ones for molecular adsorption and selfassembly. However, their different electronic properties might show up in a different reactivity towards single metallic centers and the deprotonation of carboxylic groups, preventing the formation of 2D MOFs.

\section{Acknowledgements}

We thank A. Langner, Y. Wang, M. A. Lingenfelder and G. Clarkson for fruitful discussions and W. Stiepany, P. Andler, M. Siemers and R. Chaikevitch for technical assistance. STM data were analyzed using WSxM free software. $^{50}$

\section{References}

1 R. A. Wolkow, Annu. Rev. Phys. Chem., 1999, 50, 413.

2 S. F. Bent, Surf. Sci., 2002, 500, 879.

3 T. R. Leftwich and A. V. Teplyakov, Surf. Sci. Rep., 2008, 63, 1.

4 J. T. Yates Jr, Science, 1998, 279, 335.

5 R. J. Hamers, Nature, 2001, 412, 489.

6 F. Seker, K. Meeker, T. F. Kuech and A. B. Ellis, Chem. Rev., $2000,100,2505$ 
7 G. Ashkenasy, D. Cahen, R. Cohen, A. Shanzer and A. Vilan, Acc. Chem. Res., 2002, 35, 121.

8 Y. Hirose, S. R. Forrest and A. Kahn, Phys. Rev. B, 1995, 52, 14040.

9 K. Takayanagi, Y. Tanishiro, S. Takahashi and M. Takahashi, Surf. Sci., 1985, 164, 367.

10 T. Takahashi, S. Nakatani, N. Okamoto, T. Ishikawa and S. Kikuta, Surf. Sci., 1991, 242, 54.

11 M. Eddaoudi, J. Kim, N. Rosi, D. Vodak, J. Wachter, M. O'Keeffe and O. M. Yaghi, Science, 2002, 295, 469.

12 G. Férey, C. Mellot-Draznieks, C. Serre, F. Millange, J. Dutour, S. Surblé and I. Margiolaki, Science, 2005, 309, 2040.

13 S. Clair, S. Pons, A. P. Seitsonen, H. Brune, K. Kern and J. V. Barth, J. Phys. Chem. B, 2004, 108, 14585.

14 M. E. Cañas-Ventura, F. Klappenberger, S. Clair, S. Pons, K. Kern, H. Brune, T. Strunskus, Ch. Wöll, R. Fasel and J. V. Barth, J. Chem. Phys., 2006, 125, 184710.

15 S. Stepanow, T. Strunskus, M. Lingenfelder, A. Dmitriev, H. Spillmann, N. Lin, J. V. Barth, Ch. Wöll and K. Kern, J. Phys. Chem. B, 2004, 108, 19392.

16 M. A. Lingenfelder, H. Spillmann, A. Dmitriev, S. Stepanow, N. Lin, J. V. Barth and K. Kern, Chem.-Eur. J., 2004, 10, 1913.

17 S. Stepanow, M. Lingenfelder, A. Dmitriev, H. Spillmann, E. Delvigne, N. Lin, X. Deng, C. Cai, J. V. Barth and K. Kern, Nat. Mater., 2004, 3, 229.

18 J. V. Barth, G. Costantini and K. Kern, Nature, 2005, 437, 671.

19 S. Clair, S. Pons, H. Brune, K. Kern and J. V. Barth, Angew. Chem., Int. Ed., 2005, 44, 7294.

20 S. Clair, S. Pons, S. Fabris, S. Baroni, H. Brune, K. Kern and J. V. Barth, J. Phys. Chem. B, 2006, 110, 5627.

21 T. Classen, M. Lingenfelder, Y. Wang, R. Chopra, C. Virojanadara, U. Starke, G. Costantini, G. Fratesi, S. Fabris, S. de Gironcoli, S. Baroni, S. Haq, R. Raval and K. Kern, J. Phys. Chem. A, 2007, 111, 12589.

22 A. Langner, S. L. Tait, N. Lin, C. Rajadurai, M. Ruben and K. Kern, Proc. Natl. Acad. Sci. U. S. A., 2007, 104, 17927.

23 S. L. Tait, Y. Wang, G. Costantini, N. Lin, A. Baraldi, F. Esch, L. Petaccia, S. Lizzit and K. Kern, J. Am. Chem. Soc., 2008, 130, 2108.

24 D. S. Martin, R. J. Cole and S. Haq, Phys. Rev. B, 2002, 66, 155427.

25 A. Tekiel, J. S. Prauzner-Bechcicki, S. Godlewski, J. Budzioch and M. Szymonski, J. Phys. Chem. C, 2008, 112, 12606.

26 M. Mitsuya and N. Sugita, Langmuir, 1997, 13, 7075.

27 Ph. Guaino, D. Carty, G. Hughes, P. Moriarty and A. A. Cafolla, Appl. Surf. Sci., 2003, 212-213, 537.

28 J. Teng, K. Wu, J. Guo and E. Wang, Surf. Sci., 2008, 602, 358.

29 M. D. Upward, P. Moriarty and P. H. Beton, Phy. Rev. B, 1997, 56, R1704.
30 T. Nakayama, J. Onoe, K. Takeuchi and M. Aono, Phy. Rev. B, 1999, 59, 12627.

31 K. Tsuchie, T. Nagao and S. Hasegawa, Phy. Rev. B, 1999, 60, 11131.

32 M. D. Upward, P. H. Beton and P. Moriarty, Surf. Sci., 1999, 441, 21.

33 J. B. Gustafsson, H. M. Zhang and L. S. O. Johansson, Phy. Rev. $B, 2007, \mathbf{7 5}, 155414$.

34 J. C. Swarbrick, J. Ma, J. A. Theobald, N. S. Oxtoby, J. N. O'Shea, N. R. Champness and P. H. Beton, J. Phys. Chem. B, 2005, 109, 12167.

35 L. M. A. Perdigão, P. A. Staniec, N. R. Champness, R. E. A. Kelly, L. N. Kantorovich and P. H. Beton, Phy. Rev. B, 2006, 73 , 195423.

36 G. Sheerin and A. A. Cafolla, Surf. Sci., 2005, 577, 211.

37 J. A. Theobald, N. S. Oxtoby, M. A. Phillips, N. R. Champness and P. H. Beton, Nature, 2003, 424, 1029.

38 L. M. A. Perdigão, N. R. Champness and P. H. Beton, Chem. Commun., 2006, 538.

39 S. Tanaka, M. Onchi and M. Nishijima, J. Chem. Phys., 1989, 91, 2712.

40 J. Y. Huang, H. G. Huang, K. Y. Lin, Q. P. Liu, Y. M. Sun and G. Q. Xu, Surf. Sci., 2004, 549, 255.

41 J. Y. Huang, Y. X. Shao, H. G. Huang, Y. H. Cai, Y. S. Ning, H. H. Tang, Q. P. Liu, S. F. Alshahateet, Y. M. Sun and G. Q. Xu, J. Phys. Chem. B, 2005, 109, 19831.

42 J. Y. Huang, Y. S. Ning, K. S. Yong, Y. H. Cai, H. H. Tang, Y. X. Shao, S. F. Alshahateet, Y. M. Sun and G. Q. Xu, Langmuir, 2007, 23, 6218.

43 Y. Cao, X. M. Wei, W. S. Chin, Y. H. Lai, J. F. Deng, S. L. Bernasek and G. Q. Xu, J. Phys. Chem. B, 1999, 103, 5698.

44 T. Kawasaki, D. Sakai, H. Kishimoto, A. A. Akbar, T. Ogawa and C. Oshima, Surf. Interface Anal., 2001, 31, 126.

45 S. Hasegawa, J. Phys.: Condens. Matter, 2000, 12, R463.

46 The orientation of the main molecular axis cannot be unambiguously determined from the STM topograph, but this model is the most consistent with our observations. An alternative $90^{\circ}$-rotated orientation of the molecule (which does not affect the discussion of the periodic structure and unit cell dimensions) could also be considered, but would result in dimeric H-bond lengths considerably shorter than those reported so far in the literature.

47 N. Lin, D. Payer, A. Dmitriev, T. Strunskus, C. Woll, J. V. Barth and K. Kern, Angew. Chem., Int. Ed., 2005, 44, 1488.

48 K. Vanormelingen, K. Paredis and A. Vantomme, J. Appl. Phys., 2005, 98, 024302.

49 Z. Q. Qiu, J. Pearson and S. D. Bader, Phys. Rev. Lett., 1991, 67, 1646 .

50 I. Horcas, R. Fernández, J. M. Gómez-Rodríguez, J. Colchero, J. Gómez-Herrero and A. M. Baro, Rev. Sci. Instrum., 2007, 78, 013705 . 